\title{
DESCRIPTION OF THREE NEW BISETOCREAGRIS SPECIES (PSEUDOSCORPIONES: NEOBISIIDAE) FROM SOUTHERN CHINA
}

\author{
Xiangbo Guo $^{1}$, Weitong Wang ${ }^{1}$ and Feng Zhang ${ }^{2}$ \\ ${ }^{1}$ The Key Laboratory of Invertebrate Systematics and Application, College of Life Sciences Hebei \\ University, Baoding, Hebei 071002, P. R. China; \\ E-mails: xiangboguo@163.com,weitongwang2@163.com \\ ${ }^{2}$ The Museum of Hebei University, Baoding, Hebei 071002, P. R. China; \\ E-mail:dudu06042001@163.com. Corresponding author
}

Three new Bisetocreagris species are described from southern China: Bisetocreagris shunhuangensis sp. n. from Hunan Province, B. wangi sp. n. and B. gaoi sp. n. from Guizhou Province. Detailed diagnoses, descriptions and illustrations of the three new species are presented.

Key words: taxonomy, pseudoscorpion, Bisetocreagris, new species.

\section{INTRODUCTION}

Neobisiidae is a family of medium-sized to large pseudoscorpions and mostly distributed in the Palaearctic and Nearctic ecozones. BALzAN (1892) erected the pseudoscorpion genus Microcreagris for the type species M. gigas Balzan, 1892 which is the first species of Neobisiidae reported from China. As part of partial revision of the Asian species previously assigned to the genus Microcreagris, ĆurčIĆ (1983) erected the genus Bisetocreagris for the type species B. annamensis (Beier, 1951) and six other species. Many additional species have since been added to the genus, which is widely distributed in Asia.

Bisetocreagris live in moist leaf litter, the topsoil layer and caves. At present, the genus Bisetocreagris includes 39 species and subspecies, of which 24 species (13 leaf litter inhabiting and 11 cave-inhabiting species) have been reported from China (Harvey 2013, Mahnert \& Li 2016, Guo \& Zhang 2017, GAO et al. 2017, Lr et al. 2017).

During the examination of pseudoscorpion specimens collected by sieving leaf litter from southern China, three Bisetocreagris species were found which proved to be new to science. They are described and illustrated here as B. shunhuangensis sp. n., B. wangi sp. n. and B. gaoi sp. n. 


\section{MATERIAL AND METHODS}

All specimens were examined and illustrated using a Leica 205A stereomicroscope with a drawing tube, which was also used for the measurements. Detailed examination was carried out with an Olympus BX53 general optical microscope. Temporary slide mounts were prepared in glycerol. All measurements are given in $\mathrm{mm}$. The specimens are deposited in the Museum of Hebei University (MHBU), Baoding, China, preserved in $85 \%$ alcohol.

Terminology of trichobothria follows Chamberlin (1931) and Harvey (1992). The term "rallum" (for flagellum) is adopted following Judson (2007). The following abbreviations are used in the text for the trichobothria: $b=$ basal; $s b=$ sub-basal; $s t=$ sub-terminal; $t=$ terminal; $i b=$ interior basal; $i s b=$ interior sub-basal; ist $=$ interior sub-terminal; it $=$ interior terminal; $e b=$ exterior basal; $e s b=$ exterior sub-basal; $e s t=$ exterior sub-terminal; et $=$ exterior terminal.

\section{TAXONOMY}

Family Neobisiidae Chamberlin, 1930

Bisetocreagris Ćurčić, 1983: 25.

Chinacreagris Ćurčić, 1983: 30-31 (synonymised by Harvey, 1999: 94).

Pedalocreagris Ćurčić, 1985: 349-350 (synonymised by Judson, 1993: 1207) Type species. Microcreagris annamensis Beier, 1951, by original designation.

\section{Bisetocreagris shunhuangensis sp. $\mathrm{n}$.}

(Figs 1-3)

Type material. Holotype male (Ps.-MHBU-HUN15100801), China: Hunan Province, Dong'an County, Damiaokou Town, Shunhuang Mountain $\left(26^{\circ} 26^{\prime} \mathrm{N}, 111^{\circ} 03^{\prime} \mathrm{E}\right)$, alt. 883 m, 8 October 2015, Xiangbo Guo leg. Paratypes: one male and one female (Ps.-MHBUHUN15100802-03), same data as for holotype; one female (Ps.-MHBU-HUN15100901), same locality as for holotype, 9 October 2015, Xiangbo Guo leg.

Etymology. The specific name is an adjective that refers to the type locality.

Diagnosis. Carapace with a total of $27-28$ setae, including 4 on the anterior margin and 7-8 on the posterior margin; 4 eyes, all with vaulted lens. Pedipalpal femur and patella smooth, chelal hand with fine granulations on medial face. Male pedipalpal femur 2.75-2.81 (female 2.67), patella 2.13-2.26 (female 2.04), chela (without pedicel) 2.90-2.97 (female 2.65-2.79) times longer than broad; movable finger longer than hand (without pedicel). Male fixed chelal finger with 36-37 (female 38) teeth, movable finger with 43 (female 45) small teeth.

Description. Male (Fig. 1a) - Pedipalps brown, carapace, abdomen and legs pale gray.

Carapace (Figs 2a, 3a). Smooth, 1.19 times longer than broad, with a total of 28 setae, including 4 on the anterior margin and 7-8 on the posterior margin; epistome small, triangular; 4 eyes, with vaulted lens. 
Chelicera (Figs 2b, 3b). Hand with 7 setae, movable finger with 1 seta; fixed finger with 10 teeth; movable finger with 8 teeth; serrula exterior with 28 lamellae; serrula interior with 21-23 lamellae. Galea with 8 terminal branches, structure as shown in fig. 2c. Rallum (Fig. 2e) consists of 8 blades, distalmost blade with spinules both anteriorly and posteriorly, while other blades with anteriorly-directed spinules; the basalmost blade shortest.

Pedipalps (Figs 2f, 2g, 3c, 3d). Apex of pedipalpal coxa rounded, with 3-4 setae. Femur and patella smooth, chelal hand with fine granulations on medial face. Trochanter 1.55, femur 2.75-2.81, patella 2.13-2.26, chela (with pedicel) 3.13-3.21, chela (without pedicel) 2.90-2.97 times longer than broad, movable finger 1.29-1.39 times longer than hand (without pedicel). Fixed chelal finger with 8 and movable finger with 4 trichobothria: $e b$ and $e s b$ on lateral margin of hand; $i b$, isb and ist in basal half, est in the middle, et and it in distal half of fixed finger; $t$ and $s t$ near the middle of movable finger, $s b$ and $b$ in basal half. Venom apparatus present only in fixed chelal finger, venom duct very short. Fixed chelal finger with 36-37 contiguous teeth, rounded in basal two thirds and cusped in distal third; movable finger with 43 contiguous teeth, mostly rounded, cusped only in distal end.

Abdomen. Pleural membrane granulated. Tergites and sternites with uniseriate setation, tergal chaetotaxy (I-XI): 10: 11: 11: 11: 11: 11: 11: 11: 11-12: 11: 7, sternal chaetotaxy (IV-XI): 9: 14: 15: 14: 14: 13: 12: 5; stigmata with 5-6 small setae on anterior margin, anal cone with 2 dorsal and 2 ventral setae. Male genital area (Figs 2h, 3g): sternite II with a median and posterior group of 18 setae; sternite III with an anteromedian bisetous groove, followed by 14 median and posterior setae.
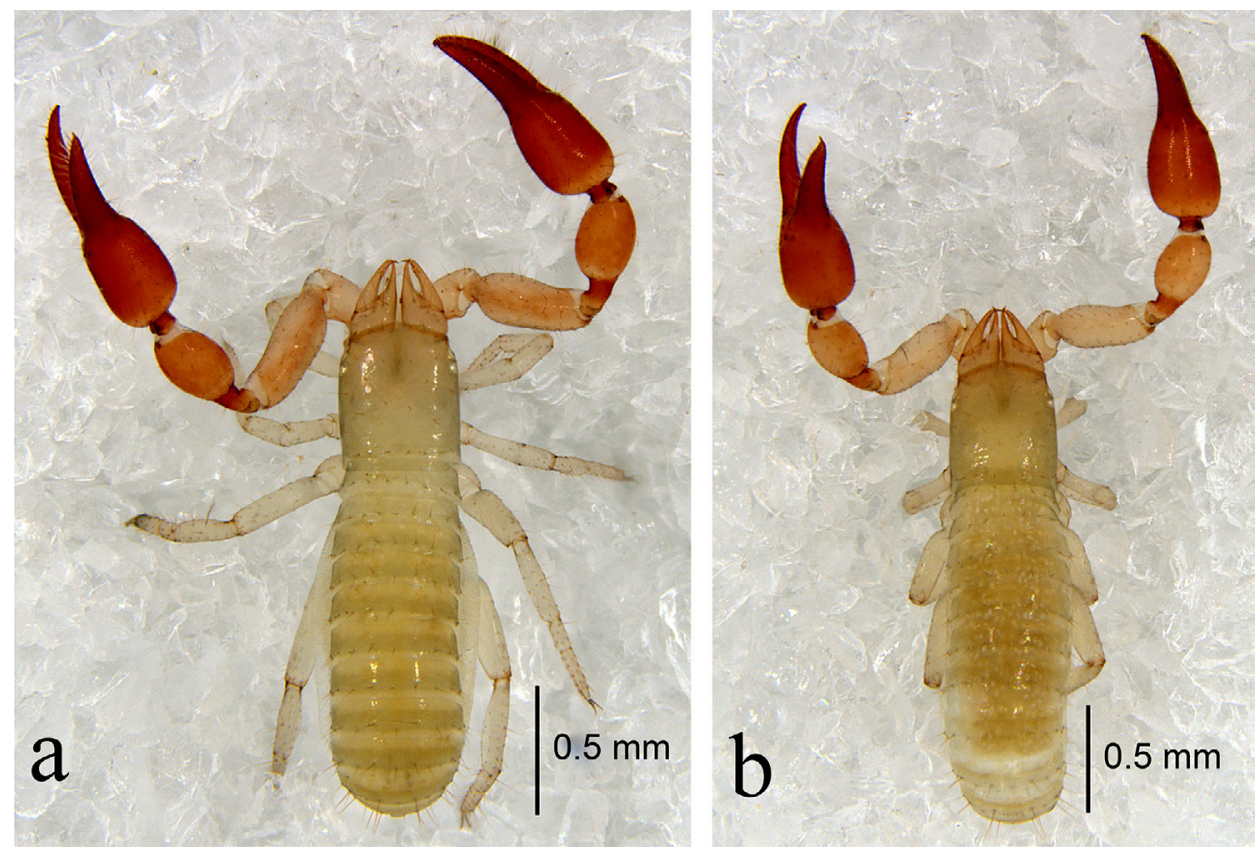

Fig. 1. Bisetocreagris shunhuangensis sp. $\mathrm{n} . \mathrm{a}=$ holotype male, habitus, dorsal view; $\mathrm{b}=$ paratype female, habitus, dorsal view 
Legs. Leg I (Fig. 3e) and leg IV (Figs 2j, 3f) typical. Tibia IV with one medial tactile seta $(T S=0.49)$, basitarsus IV with a basal tactile seta $(T S=0.20)$, telotarsus IV with one sub-medial tactile seta (TS $=0.37)$. Subterminal tarsal seta bifurcate; arolium not divided, shorter than the slender and simple claws.

Female (Fig. 1b) - As in holotype except where noted.

Chelicera. Fixed finger with 9 teeth; movable finger with 8 teeth; serrula exterior with 27 lamellae; serrula interior with 23 lamellae. Galea with 8 terminal branches, structure as shown in Fig. 2d.
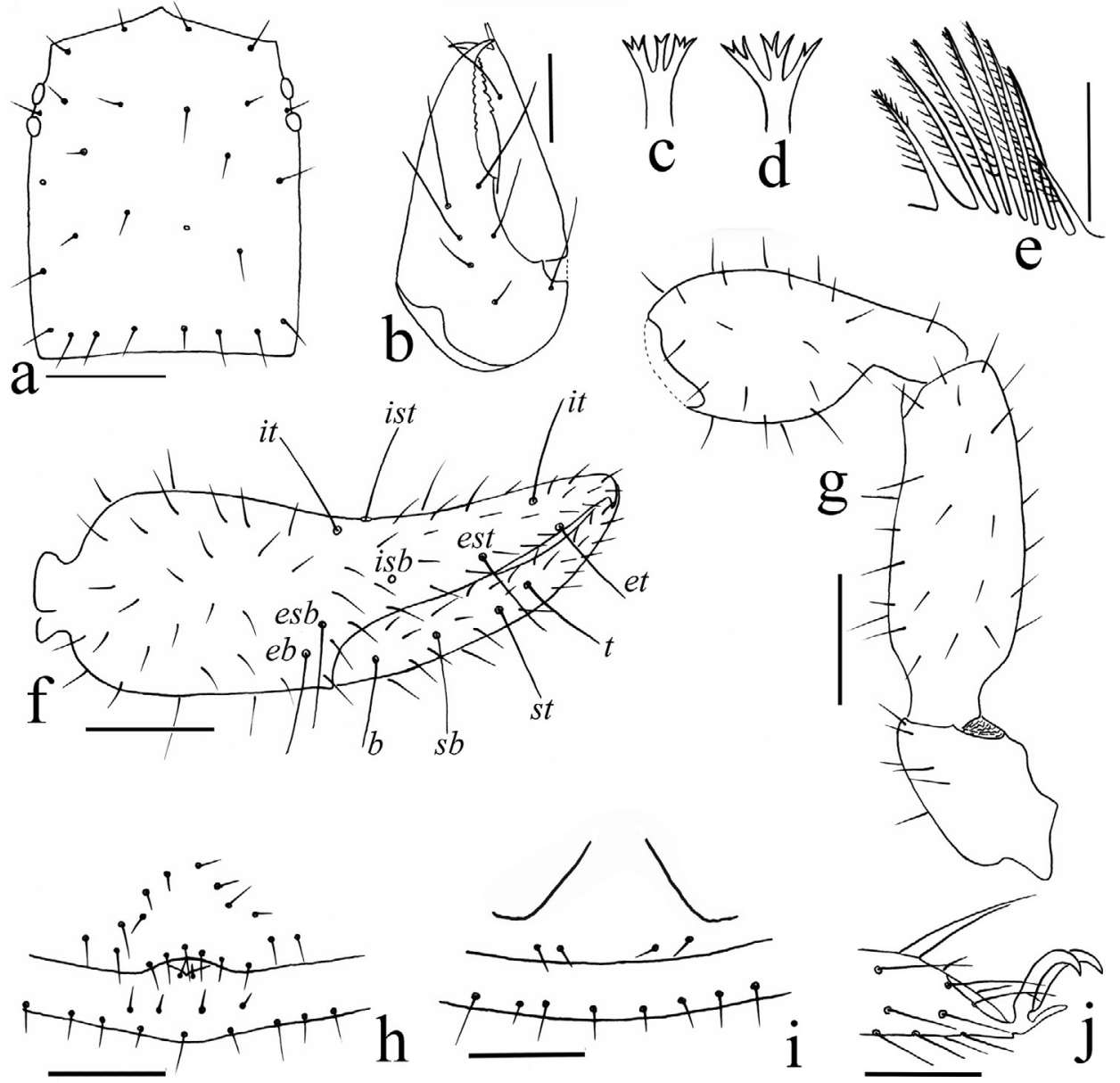

Fig. 2. Bisetocreagris shunhuangensis sp. n., holotype male (Figs. a-c, e-h, j), paratype female (Figs. $\mathrm{d}, \mathrm{i}$ ): $\mathrm{a}=$ carapace, dorsal view; $\mathrm{b}=$ right chelicera, dorsal view; $\mathrm{c}=$ galea of male; $\mathrm{d}=$ galea of female; $\mathrm{e}=$ rallum; $\mathrm{f}=$ right chela, lateral view, showing trichobothriotaxy; $\mathrm{g}=$ right pedipalp, dorsal view (trochanter, femur and patella); $\mathrm{h}=$ genital area of male; $\mathrm{i}=$ genital area of female; $j=$ tip of telotarsus IV, lateral view. Scale bars: $0.05 \mathrm{~mm}(\mathrm{e}) ; 0.10 \mathrm{~mm}(\mathrm{~b}, \mathrm{~h}-\mathrm{j})$; $0.20 \mathrm{~mm}(\mathrm{a}, \mathrm{f}, \mathrm{g})$ 
Pedipalps. Trochanter 1.75-1.85, femur 2.67, patella 2.04, chela (with pedicel) 2.853.03, chela (without pedicel) 2.65-2.79 times longer than broad, movable finger 1.20-1.21 times longer than hand (without pedicel). Fixed chelal finger with 38 contiguous teeth, rounded in basal two thirds and cusped in distal third; movable finger with 45 contiguous teeth, mostly rounded, cusped only in distal end.

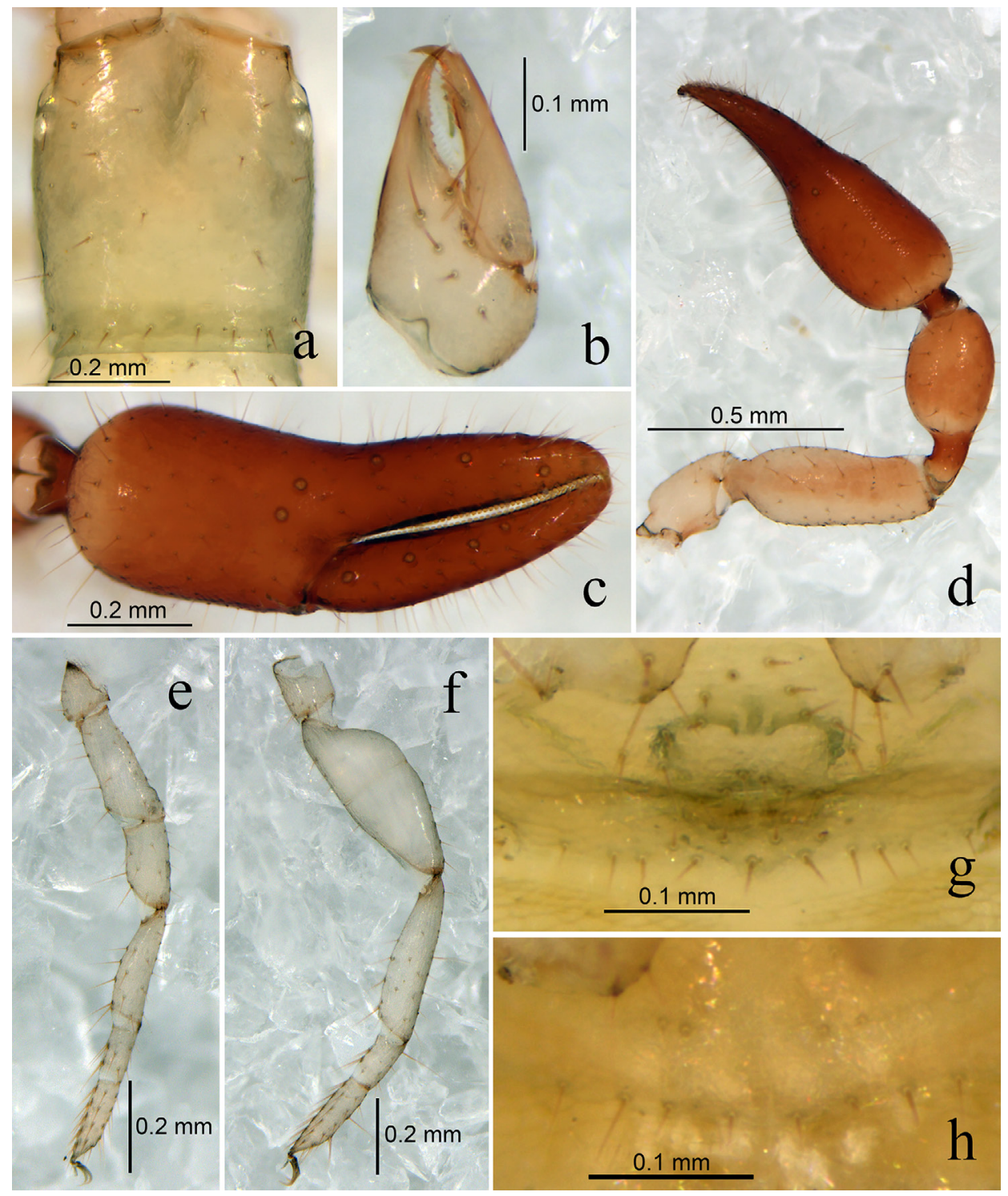

Fig. 3. Bisetocreagris shunhuangensis sp. n., holotype male (Figs a-g), paratype female (Fig. h): $\mathrm{a}=$ carapace, dorsal view; $\mathrm{b}=$ right chelicera, dorsal view; $\mathrm{c}=$ right chela, lateral view; $\mathrm{d}=$ right pedipalp, dorsal view; $\mathrm{e}=$ leg $\mathrm{I}$, lateral view; $\mathrm{f}=$ leg $\mathrm{IV}$, lateral view; $\mathrm{g}$ = genital area of male; $h=$ genital area of female 
Abdomen. Tergal chaetotaxy (I-XI): 10: 11: 11: 11-12: 11: 11-12: 11: 11: 12: 12: 7, sternal chaetotaxy (IV-XI): 10: 14-16: 15: 16: 16: 15: 13: 5. Female genital area (Figs 2i, 3h): sternite II with 2 setae on each side; sternite III with a row of 8 setae on the posterior margin.

Measurements (length/breadth or depth in $\mathrm{mm}$, ratios in parentheses). Male. Body length $1.90-2.02$. Carapace $0.56 \times 0.47$ (1.19). Chelicera 0.36-0.37×0.19 (1.89-1.95), movable finger length 0.26 . Pedipalpal trochanter $0.31 \times 0.20$ (1.55), femur $0.55-0.59 \times 0.20-0.21(2.75$ 2.81), patella $0.49-0.52 \times 0.23(2.13-2.26)$, chela (with pedicel) $0.93-0.97 \times 0.29-0.31(3.13-3.21)$, chela (without pedicel) $0.86-0.90 \times 0.29-0.31(2.90-2.97)$, hand length (without pedicel) 0.38 , movable finger length $0.49-0.53(1.29-1.39 \times$ hand $)$. Leg I: trochanter $0.14 \times 0.10(1.40)$, femur $0.28-0.30 \times 0.12(2.33-2.50)$, patella $0.20 \times 0.10(2.00)$, tibia $0.27-0.28 \times 0.07(3.86-4.00)$, basitarsus $0.12 \times 0.05(2.40)$, telotarsus $0.19-0.21 \times 0.05(3.80-4.20)$. Leg IV: trochanter $0.16 \times 0.13$ (1.23), femur + patella $0.54-0.59 \times 0.21-0.22(2.57-2.68)$, tibia $0.45-0.47 \times 0.11(4.09-4.27)$, basitarsus $0.15 \times 0.08(1.88)$, telotarsus $0.27 \times 0.07(3.86)$.

Female. Body length 2.09-2.17. Carapace 0.60-0.63×0.49-0.51 (1.22-1.24). Chelicera $0.39 \times 0.20$ (1.95), movable finger length 0.28 . Pedipalpal trochanter $0.35-0.37 \times 0.20(1.75$ 1.85), femur $0.56 \times 0.21(2.67)$, patella $0.49 \times 0.24$ (2.04), chela (with pedicel) $0.97-1.03 \times 0.34$ (2.85-3.03), chela (without pedicel) $0.90-0.95 \times 0.34(2.65-2.79)$, hand length (without pedicel) $0.41-0.43$, movable finger length $0.49-0.52(1.20-1.21 \times$ hand $)$. Leg I: trochanter $0.14 \times 0.10$ (1.40), femur $0.28 \times 0.12$ (2.33), patella $0.22 \times 0.11$ (2.00), tibia $0.27-0.29 \times 0.07(3.86-4.14)$, basitarsus $0.12 \times 0.06(2.00)$, telotarsus $0.19 \times 0.06$ (3.17). Leg IV: trochanter $0.19 \times 0.14(1.36)$, femur + patella $0.55-0.58 \times 0.21-0.23(2.52-2.62)$, tibia $0.46-0.48 \times 0.11(4.18-4.36)$, basitarsus $0.15 \times 0.08(1.88)$, telotarsus $0.27 \times 0.07(3.86)$.

\section{Distribution. China (Hunan).}

Remarks. The other Bisetocreagris species with comparable pedipalpal size (pedipalpal femur 0.55-0.59, patella 0.49-0.52 $\mathrm{mm}$ in length) are $B$. pygmaea (Ellingsen, 1907), B. philippinensis (Beier, 1931), B. afghanica (Beier, 1959), B. furax (Beier, 1959), B. klapperichi (Beier, 1959) and B. thailandica Schwaller, 1994. Bisetocreagris shunhuangensis can be distinguished from these species by: pedipalpal femur smooth (pedipalpal femur with granulations in B. philippinensis, B. furax, B. klapperichi and B. pygmaea); pedipalpal femur 2.67-2.81 (4.20 in B. furax; 3.60 in B. afghanica; 4.00 in B. klapperichi) times longer than broad; pedipalpal femur obviously longer than patella (femur shares with patella a similar length in $B$. thailandica); fixed chelal finger with 36-38, movable finger with 43-45 teeth (chelal finger with 50-54 teeth in B. philippinensis; chelal finger with $45-50$ teeth in B. thailandica).

\section{Bisetocreagris wangi sp. $n$.}

(Figs 4-6)

Type material. Holotype male (Ps.-MHBU-GZ13100501), China: Guizhou Province, Songtao County, Wuluo Town $\left(28^{\circ} 01^{\prime} \mathrm{N}, 108^{\circ} 45^{\prime} \mathrm{E}\right)$, alt. $1239 \mathrm{~m}, 5$ October 2013, Luyu Wang leg. Paratypes: four males and three females (Ps.-MHBU- GZ13100502-08), same data as for holotype; one male and four females (Ps.-MHBU- GZ14101101-05), same locality as for holotype, 1 November 2014, Zhizhong Gao leg. 
Etymology. The specific name is a patronym in honor of Dr. Luyu Wang, who collected the holotype of this species.

Diagnosis. Carapace with a total of 28-29 setae, including 4 on the anterior margin and 8-9 on the posterior margin; 4 eyes, anterior pair with vaulted lens, posterior pair with flattened lens. Pedipalpal femur and patella with granulations on medial face, chelal hand with granulations on medial and lateral face. Male pedipalpal femur 2.77-3.05 (female 2.77-2.87), patella 2.12 (female 1.93-2.04), chela (without pedicel) 2.91-2.94 (female 2.65-2.69) times longer than broad; movable finger longer than hand (without pedicel). Male fixed chelal finger with 44-48 (female 43-49) teeth, movable finger with 46-51 (female 48-54) small teeth.

Description. Male (Fig. 4a) - Pedipalps, carapace and chelicerae yellowish brown, abdomen and legs pale yellow.

Carapace (Figs 5b, 6a). Smooth, 1.19 times longer than broad, with a total of 28-29 setae, including 4 on the anterior margin and 8-9 on the posterior margin; epistome small, triangular; 4 eyes, anterior pair with vaulted lens, posterior pair with flattened lens.
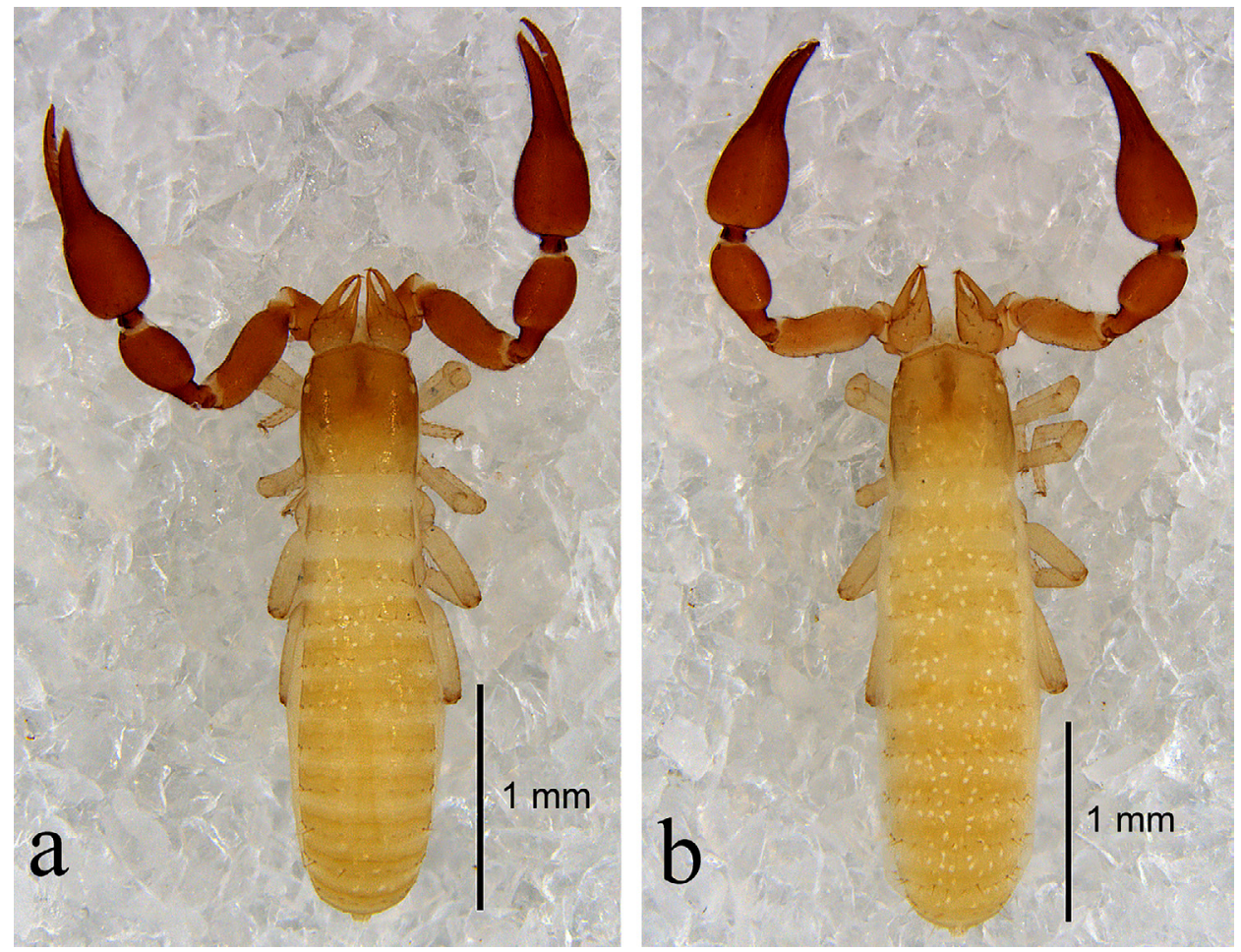

Fig. 4. Bisetocreagris wangi sp. n.: a = holotype male, habitus, dorsal view; $b=$ paratype female, habitus, dorsal view 
Chelicera (Figs 5c, 6b). Hand with 7 setae, movable finger with 1 seta; fixed finger with 8 teeth; movable finger with 10-11 teeth; serrula exterior with 28-31 lamellae; serrula interior with 25-26 lamellae. Galea with 5 small terminal branches, structure as shown in fig. 5d. Rallum (Fig. 5g) with 8 blades, all with anteriorly-directed spinules, the basalmost blade shortest.

Pedipalps (Figs 5a, 5f, 6c, 6d). Apex of pedipalpal coxa rounded, with 3-4 setae. Pedipalpal femur and patella with granulations on medial face, chelal hand with granulations on medial and lateral face. Trochanter 1.61-1.64, femur 2.77-3.05, patella 2.12, chela (with pedicel) 3.06-3.12, chela (without pedicel) 2.91-2.94 times longer than broad, movable finger 1.24-1.30 times longer than hand (without pedicel). Fixed chelal finger with 8 and movable finger with 4 trichobothria: $e b$ and $e s b$ on lateral margin of hand; $i b$, is $b$ and ist in basal half, est in the middle, et and it in distal half of fixed finger; $t$ and st near the middle of
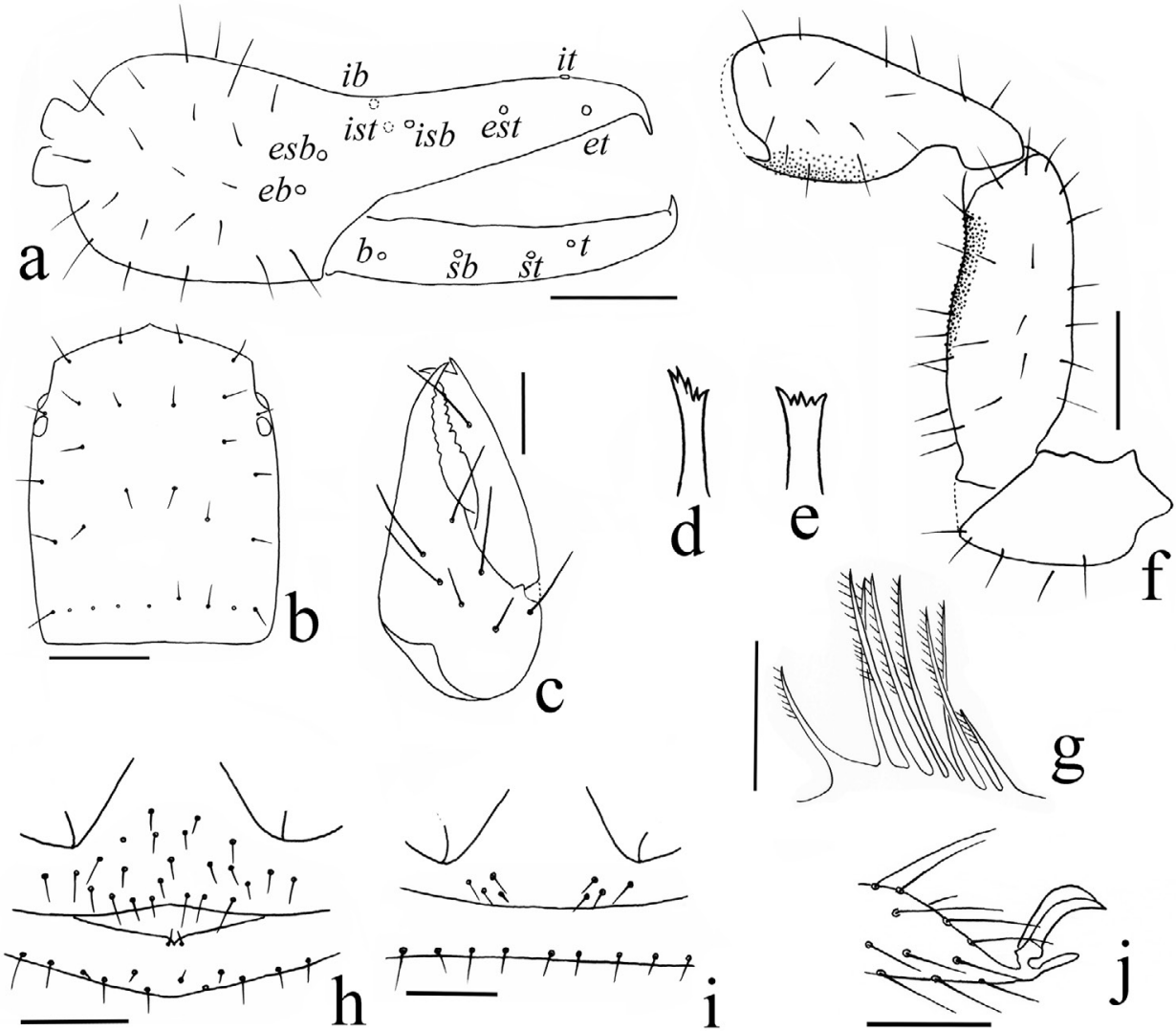

Fig. 5. Bisetocreagris wangi sp. n., holotype male (Figs a-d, $\mathrm{f}-\mathrm{h}, \mathrm{j}$ ), paratype female (Figs. e, i): $a$ = right chela, lateral view, showing trichobothriotaxy; $b=$ carapace, dorsal view; $c=$ right chelicera, dorsal view; $\mathrm{d}=$ galea of male; $\mathrm{e}=$ galea of female; $\mathrm{f}=$ right pedipalp, dorsal view (trochanter, femur and patella); $g=$ rallum; $h=$ genital area of male; $i=$ genital area of female; $j$ = tip of telotarsus IV, lateral view. Scale bars: $0.05 \mathrm{~mm}(\mathrm{~g}) ; 0.10 \mathrm{~mm}(\mathrm{c}, \mathrm{h}-\mathrm{j}) ; 0.20$ $\mathrm{mm}(\mathrm{a}, \mathrm{b}, \mathrm{f})$ 
movable finger, $s b$ and $b$ in basal half. Venom apparatus present only in fixed chelal finger, venom duct very short. Fixed chelal finger with $44-48$ contiguous teeth, rounded in basal two thirds and cusped in distal third; movable finger with 46-51 contiguous teeth, mostly rounded, cusped only in distal end.

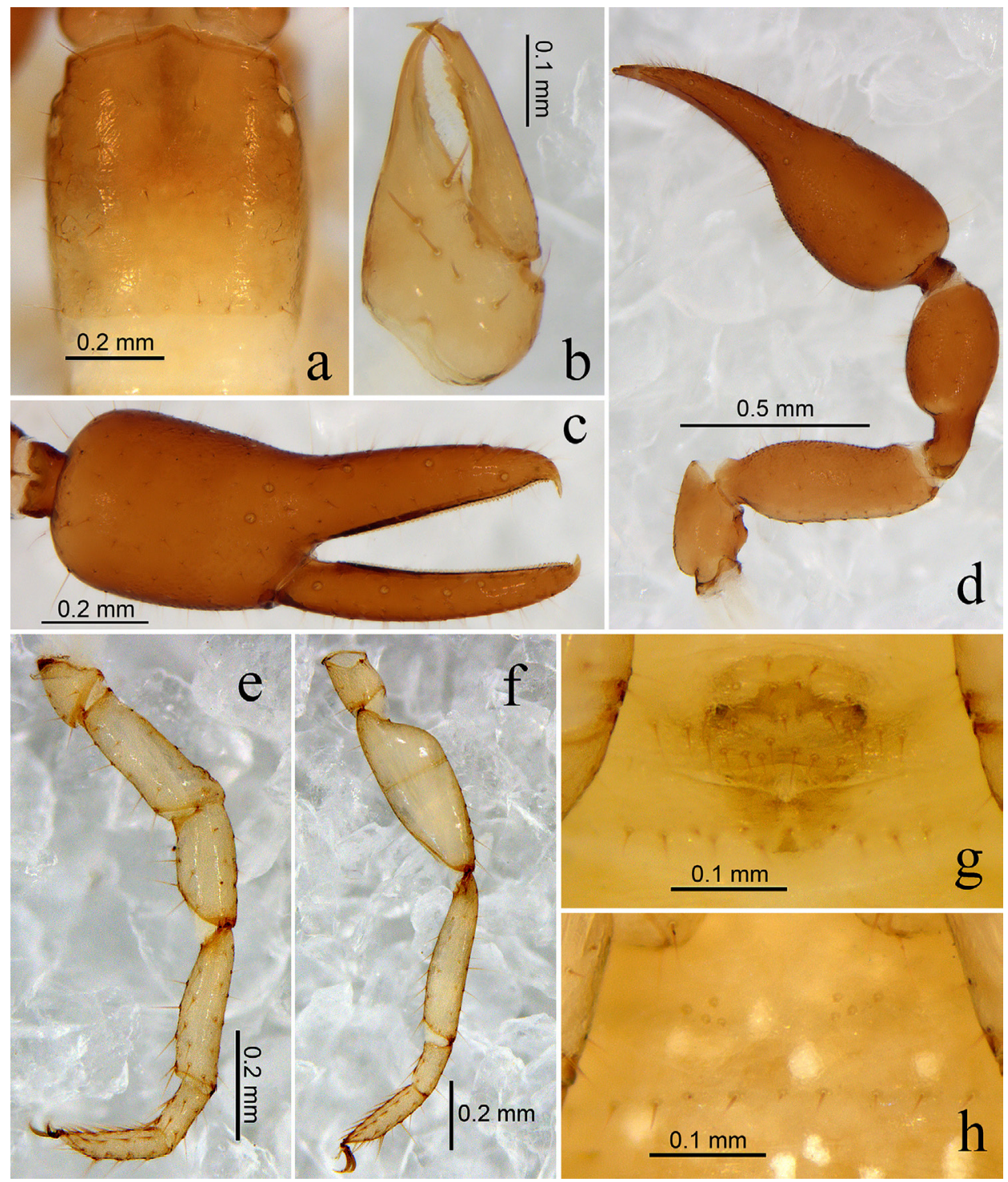

Fig. 6. Bisetocreagris wangi sp. n., holotype male (Figs a-g), paratype female (Fig. $\mathrm{h}$ ): $\mathrm{a}=$ carapace, dorsal view; $b=$ right chelicera, dorsal view; $c=$ right chela, lateral view; $d=$ right pedipalp, dorsal view; $\mathrm{e}=$ leg I, lateral view; $\mathrm{f}=\operatorname{leg} \mathrm{IV}$, lateral view; $\mathrm{g}=$ genital area of male; $\mathrm{h}=$ genital area of female 
Abdomen. Pleural membrane granulated. Tergites and sternites with uniseriate setation, tergal chaetotaxy (I-XI): 11: 11: 11-12: 12: 12: 12: 12: 12: 13: 13-14: 7, sternal chaetotaxy (IV-XI): 10: 13-14: 17: 16: 16-18: 16: 14: 5; stigmata with 4 small setae on anterior margin, anal cone with 2 dorsal and 2 ventral setae. Male genital area (Figs 5h, 6g): sternite II with a median and posterior group of 20-24 setae; sternite III with an anteromedian bisetous groove, followed by 13-15 median and posterior setae.

Legs. Leg I (Fig. 6e) and leg IV (Figs 5j, 6f) typical. Tibia IV with one medial tactile seta (TS $=0.51-0.55)$, basitarsus IV with one tactile seta in basal half $(\mathrm{TS}=0.19)$, telotarsus IV with one sub-medial tactile seta (TS $=0.32-0.39$ ). Subterminal tarsal seta bifurcate; arolium not divided, shorter than the slender and simple claws.

Female (Fig. 4b) - As in holotype except where noted.

Chelicera. Fixed finger with 8-9 teeth; movable finger with 12 teeth; serrula exterior with 27-29 lamellae; serrula interior with 20-23 lamellae. Galea with 5 small terminal branches, structure as shown in fig. $5 \mathrm{e}$.

Pedipalps. Trochanter 1.61-1.79, femur 2.77-2.87, patella 1.93-2.04, chela (with pedicel) 2.81-2.87, chela (without pedicel) 2.65-2.69 times longer than broad, movable finger 1.20-1.21 times longer than hand (without pedicel). Fixed chelal finger with 43-49 contiguous teeth, rounded in basal two thirds and cusped in distal third; movable finger with 48-54 contiguous teeth, mostly rounded, cusped only in distal end.

Abdomen. Tergal chaetotaxy (I-XI): 11: 11-12: 11-12: 12: 12: 12-13: 12: 12: 13: 13-14: 7, sternal chaetotaxy (IV-XI): 10: 14: 15-16: 16: 16: 15-16: 14: 5. Female genital area (Figs $5 \mathrm{i}, 6 \mathrm{~h}$ ): sternite II with $4-5$ setae on each side; sternite III with a row of 9-11 setae on the posterior margin.

Measurements (length/breadth or depth in mm). Male. Body length 2.07-2.59. Carapace $0.62-0.63 \times 0.52-0.53(1.19)$. Chelicera $0.41 \times 0.19(2.16)$, movable finger length 0.27 . Pedipalpal trochanter $0.36-0.37 \times 0.22-0.23(1.61-1.64)$, femur $0.61 \times 0.20-0.22(2.77-3.05)$, patella $0.53 \times 0.25$ (2.12), chela (with pedicel) 1.01-1.06 $\times 0.33-0.34$ (3.06-3.12), chela (without pedicel) $0.96-1.00 \times 0.33-0.34$ (2.91-2.94), hand length (without pedicel) $0.42-0.43$, movable finger length $0.52-0.56(1.24-1.30 \times$ hand). Leg I: trochanter $0.14 \times 0.11-0.12(1.17-1.27)$, femur $0.30 \times 0.12(2.50)$, patella $0.23-0.24 \times 0.10-0.11(2.18-2.30)$, tibia $0.29-0.30 \times 0.08$ (3.633.75), basitarsus $0.13-0.15 \times 0.06(2.17-2.50)$, telotarsus $0.20-0.22 \times 0.05(4.00-4.40)$. Leg IV: trochanter $0.16-0.18 \times 0.12-0.13(1.33-1.38)$, femur + patella $0.58 \times 0.20-0.21(2.76-2.90)$, tibia $0.49-0.51 \times 0.10-0.11(4.64-4.90)$, basitarsus $0.16 \times 0.08(2.00)$, telotarsus $0.28 \times 0.07(4.00)$.

Female. Body length 2.74-2.97. Carapace 0.62-0.68×0.60-0.62 (1.03-1.20). Chelicera $0.45 \times 0.20$ (2.25), movable finger length 0.27 . Pedipalpal trochanter $0.37-0.43 \times 0.23-0.24(1.61-$ 1.79), femur $0.61-0.66 \times 0.22-0.23(2.77-2.87)$, patella $0.53-0.54 \times 0.26-0.28(1.93-2.04)$, chela (with pedicel) $1.04-1.12 \times 0.37-0.39$ (2.81-2.87), chela (without pedicel) $0.98-1.05 \times 0.37-0.39$ (2.65-2.69), hand length (without pedicel) $0.44-0.48$, movable finger length $0.53-0.58$ (1.20$1.21 \times$ hand). Leg I: trochanter $0.14 \times 0.11(1.27)$, femur $0.30 \times 0.12(2.50)$, patella $0.23-0.24 \times 0.10$ (2.30-2.40), tibia $0.29-0.30 \times 0.08(3.63-3.75)$, basitarsus $0.14 \times 0.06$ (2.33), telotarsus 0.20 $0.21 \times 0.05(4.00-4.20)$. Leg IV: trochanter $0.18 \times 0.13(1.38)$, femur + patella $0.58 \times 0.20-0.21(2.76-$ $2.90)$, tibia $0.49-0.50 \times 0.10(4.90-5.00)$, basitarsus $0.16 \times 0.08(2.00)$, telotarsus $0.28 \times 0.07(4.00)$.

\section{Distribution. China (Guizhou).}

Remarks. The other Bisetocreagris species with comparable pedipalpal size (pedipalpal femur 0.61-0.66, patella $0.53-0.54 \mathrm{~mm}$ in length) are $B$. pygmaea, B. turkestanica (Beier, 1929), B. philippinensis, B. furax, B. klapperichi, B. 
parablothroides (Beier, 1951) and B. shunhuangensis. Bisetocreagris wangi can be distinguished from these species by: carapace with 28-29 setae (24-26 in $B$. pygmaea; 22 in B. philippinensis; 22 in B. klapperichi; 25 in B. furax); pedipalpal femur with granulations on medial face (pedipalpal femur smooth in $B$. shunhuangensis); pedipalpal patella with granulations on medial face (pedipalpal patella smooth in B. furax, B. klapperichi and B. shunhuangensis); pedipalpal femur 2.77-3.05 (3.50 in B. turkestanica; 3.40-3.50 in B. philippinensis; 4.00 in B. klapperichi; 4.20 in B. furax) times longer than broad; chelal finger longer than hand (chelal finger equal in length to hand in B. parablothroides and B. klapperichi); fixed chelal finger with 43-49, movable finger with $46-54$ teeth (chelal finger with 55-60 teeth in B. parablothroides).

\section{Bisetocreagris gaoi sp. $\mathrm{n}$.}

(Figs 7-9)

Type material. Holotype male (Ps.-MHBU-GZ14101301), China: Guizhou Province, Jiangkou County, Fanjing Mountain $\left(27^{\circ} 55^{\prime} \mathrm{N}, 108^{\circ} 40^{\prime} \mathrm{E}\right)$, alt. $2024 \mathrm{~m}, 13$ October 2014, Zhizhong Gao leg. Paratypes: three males and five females (Ps.- MHBU- GZ14101302-09), same data as for holotype.

Etymology. The specific name is a patronym in honor of Dr. Zhizhong Gao, who collected the specimens.

Diagnosis. Carapace with a total of 27 setae, including 6 on the anterior margin and 6 on the posterior margin; 4 eyes, with vaulted lens. Pedipalpal femur with granulations on medial face, patella and chelal hand smooth. Male pedipalpal femur 4.05-4.17 (female 3.87-4.17), patella 2.96-3.00 (female 2.63-2.66), chela (without pedicel) 4.00-4.08 (female 3.33-3.38) times longer than broad; movable finger longer than hand (without pedicel). Male fixed chelal finger with 62-65 (female 65-67) teeth, movable finger with 66-70 (female 66-67) small teeth.

Description. Male (Fig. 7a) - Pedipalps and chelicerae yellowish brown, carapace and abdomen darker, legs pale brown.

Carapace (Figs 8d, 9a). Smooth, 1.15 times longer than broad, with a total of 27 setae, including 6 on the anterior margin and 6 on the posterior margin; epistome small, triangular; 4 eyes, with vaulted lens.

Chelicera (Figs 8a, 9b). Hand with 7 setae, movable finger with 1 seta; fixed finger with 10 teeth; movable finger with 6 teeth; serrula exterior with 26-29 lamellae; serrula interior with 22-25 lamellae. Galea with 4 small terminal branches, structure as shown in Fig. 8e. Rallum (Fig. 8g) with 8 blades, all with anteriorly-directed spinules, the basalmost blade shortest.

Pedipalps (Figs 8b, 8c, 9c, 9d). Apex of pedipalpal coxa rounded, with $4-5$ setae. Pedipalpal femur with granulations on medial face, patella and chelal hand smooth. Trochanter 1.60-1.67, femur 4.05-4.17, patella 2.96-3.00, chela (with pedicel) 4.28-4.38, chela (without 
pedicel) 4.00-4.08 times longer than broad, movable finger 1.46-1.56 times longer than hand (without pedicel). Fixed chelal finger with 8 and movable finger with 4 trichobothria: $e b$ and $e s b$ on lateral margin of hand; $i b$, is $b$ and ist in basal half, est in the middle, et and it in distal half of fixed finger; $t$ and $s t$ near the middle of movable finger, $s b$ and $b$ in basal half. Venom apparatus present only in fixed chelal finger, venom duct very short. Fixed chelal finger with 62-65 and movable finger with 66-70 contiguous teeth, mostly rounded, cusped only in distal end.

Abdomen. Pleural membrane granulated. Tergites and sternites with uniseriate setation, tergal chaetotaxy (I-XI): 10: 11: 11: 12: 12: 12: 12: 12-13: 12-13: 12: 5, sternal chaetotaxy (IV-XI): 11: 16: 15: 15-16: 16: 16: 13: 6; stigmata with 4-5 small setae on anterior margin, anal cone with 2 dorsal and 2 ventral setae. Male genital area (Figs 8h, 9g): sternite II with a median and posterior group of 28-30 setae; sternite III with an anteromedian bisetous groove, followed by 16 median and posterior setae.

Legs. Leg I (Fig. 9e) and leg IV (Figs 8j, 9f) typical. Tibia IV with one sub-medial tactile seta (TS $=0.43-0.44)$, basitarsus IV with one tactile seta in basal half $(\mathrm{TS}=0.15)$, telotarsus IV with one sub-medial tactile seta $(\mathrm{TS}=0.43-0.44)$. Subterminal tarsal seta bifurcate; arolium not divided, shorter than the slender and simple claws.

Female (Fig. 7b) - As in holotype except where noted.

Chelicera. Fixed finger with 7 teeth; movable finger with 6 teeth; serrula exterior with 28-30 lamellae; serrula interior with 23-26 lamellae. Galea with 5 terminal branches, structure as shown in fig. $8 \mathrm{f}$.

Pedipalps. Trochanter 1.61-1.68, femur 3.87-4.17, patella 2.63-2.66, chela (with pedicel) 3.57-3.64, chela (without pedicel) 3.33-3.38 times longer than broad, movable finger
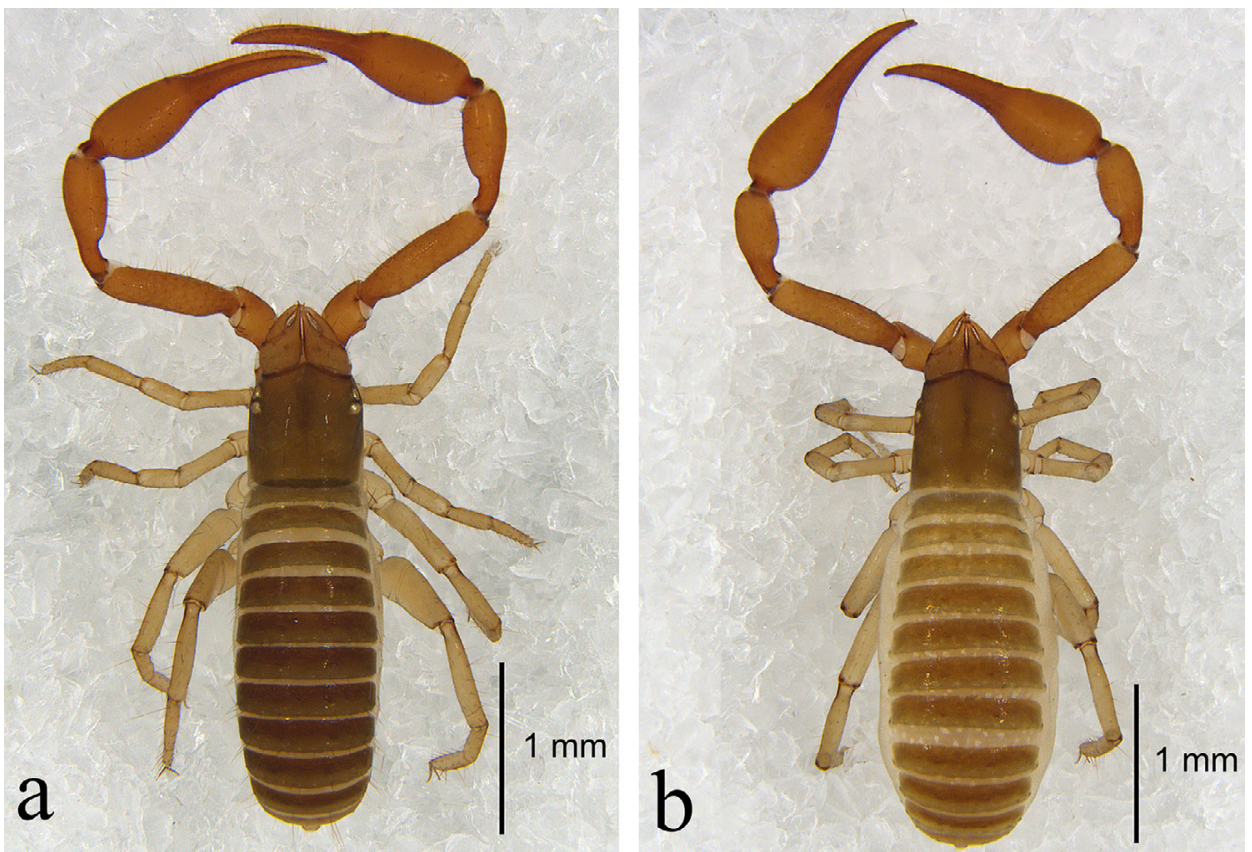

Fig. 7. Bisetocreagris gaoi sp. n.: a = holotype male, habitus, dorsal view; $b=$ paratype female, habitus, dorsal view 
1.25-1.27 times longer than hand (without pedicel). Fixed chelal finger with 65-67 and movable finger with 66-67 contiguous teeth, mostly rounded, cusped only in distal end.

Abdomen. Tergal chaetotaxy (I-XI): 10: 11: 11-12: 12: 12: 12: 12-13: 12: 13: 13: 5, sternal chaetotaxy (IV-XI): 11: 15: 16: 15-16: 15-16: 15: 14: 6. Female genital area (Figs 8i, 9h): sternite II with $4-5$ setae on each side; sternite III with a row of 10 setae on the posterior margin.

Measurements (length/breadth or depth in mm). Male. Body length 2.51-2.77. Carapace $0.78 \times 0.68(1.15)$. Chelicera $0.49-0.53 \times 0.26(1.88-2.04)$, movable finger length $0.31-0.33$. Pedipalpal trochanter $0.48-0.50 \times 0.30$ (1.60-1.67), femur 0.89-0.96 $\times 0.22-0.23$ (4.05-4.17), patella $0.77-0.78 \times 0.26(2.96-3.00)$, chela (with pedicel) $1.54-1.62 \times 0.36-0.37(4.28-4.38)$, chela (without pedicel) $1.44-1.51 \times 0.36-0.37(4.00-4.08)$, hand length (without pedicel) 0.59 , movable finger length $0.86-0.92(1.46-1.56 \times$ hand $)$. Leg I: trochanter $0.20-0.21 \times 0.16(1.25-1.31)$, femur $0.45-0.47 \times 0.15-0.16(2.94-3.00)$, patella $0.30 \times 0.13(2.31)$, tibia $0.36-0.40 \times 0.10(3.60-$

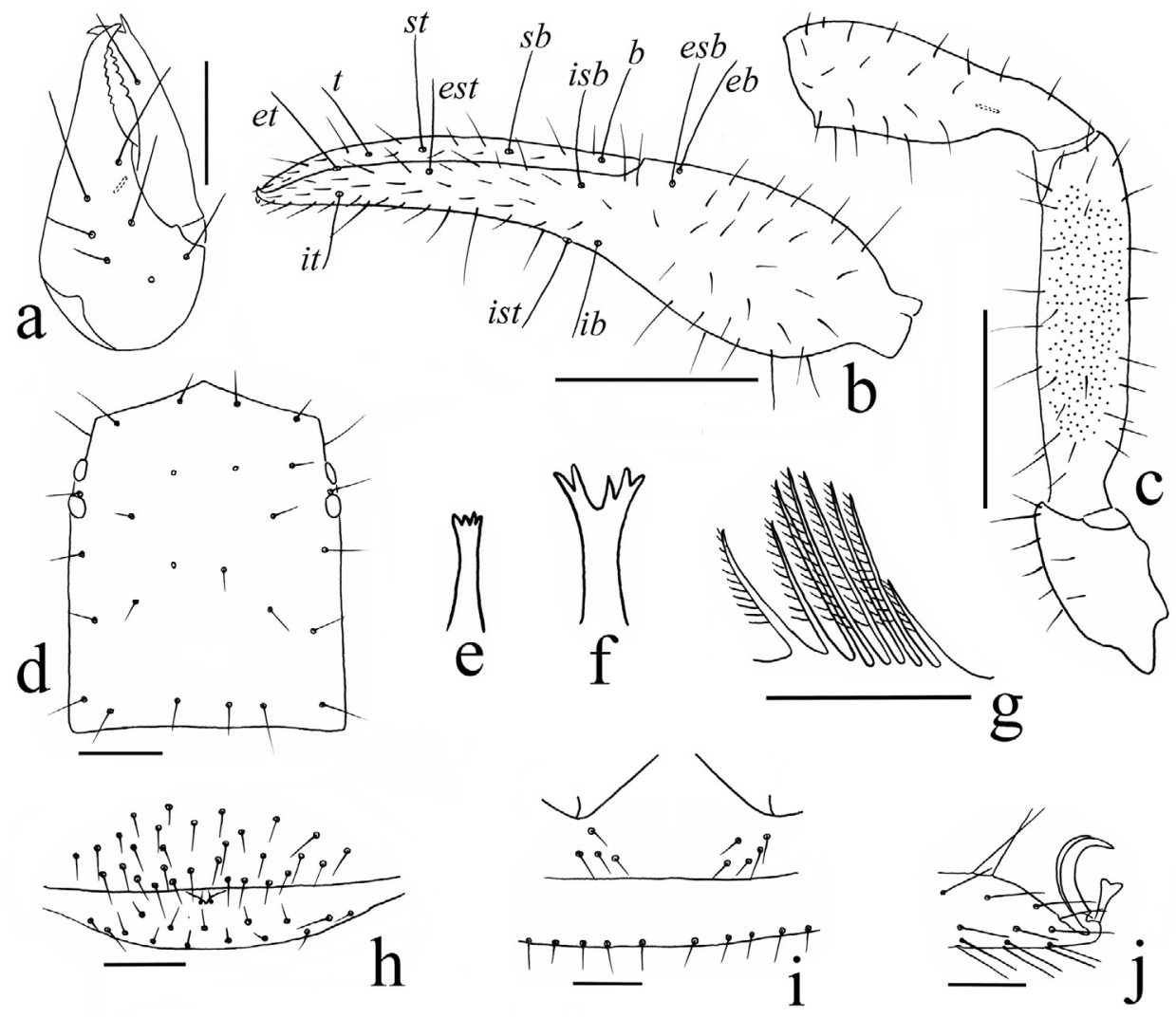

Fig. 8. Bisetocreagris gaoi sp. n., holotype male (Figs a-e, g, h, j), paratype female (Figs f, i): $\mathrm{a}=$ right chelicera, dorsal view; $\mathrm{b}=$ right chela, dorsal view, showing trichobothriotaxy; $\mathrm{c}=$ right pedipalp, dorsal view (trochanter, femur and patella); $\mathrm{d}=$ carapace, dorsal view; $\mathrm{e}=$ galea of male; $\mathrm{f}=$ galea of female; $\mathrm{g}=$ rallum; $\mathrm{h}=$ genital area of male; $\mathrm{i}=$ genital area of female; $j=$ tip of telotarsus IV, lateral view. Scale bars: $0.10 \mathrm{~mm}(\mathrm{~g}-\mathrm{j}) ; 0.20 \mathrm{~mm}(\mathrm{a}, \mathrm{d}) ; 0.50$ $\mathrm{mm}(\mathrm{b}, \mathrm{c})$ 
4.00), basitarsus $0.19-0.22 \times 0.07(2.71-3.14)$, telotarsus $0.31 \times 0.07$ (4.43). Leg IV: trochanter $0.26 \times 0.19(1.37)$, femur + patella $0.84-0.86 \times 0.28-0.29(2.97-3.00)$, tibia $0.65-0.68 \times 0.14(4.64-$ $4.86)$, basitarsus $0.26-0.28 \times 0.11(2.36-2.55)$, telotarsus $0.37-0.41 \times 0.10(3.70-4.10)$.
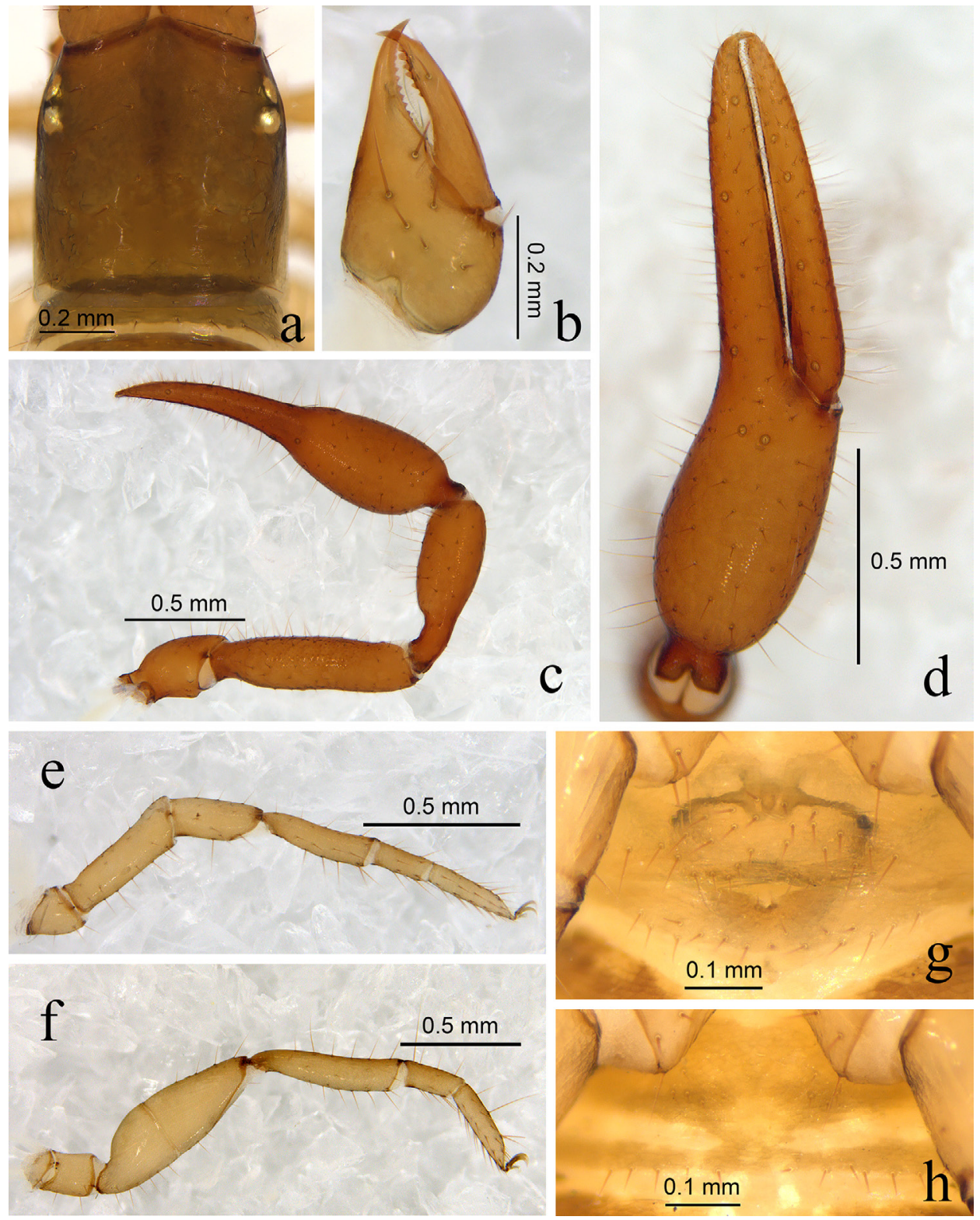

Fig. 9. Bisetocreagris gaoi sp. n., holotype male (Figs a-g), paratype female (Fig. h): a = carapace, dorsal view; $b=$ right chelicera, dorsal view; $c=$ right pedipalp, dorsal view; $d=$ right chela, lateral view; e = leg I, lateral view; $\mathrm{f}=$ leg IV, lateral view; $\mathrm{g}=$ genital area of male; $\mathrm{h}=$ genital area of female 
Female. Body length 2.86-3.04. Carapace 0.85-0.88×0.72-0.77 (1.14-1.18). Chelicera: $0.52-0.57 \times 0.26-0.28(2.00-2.04)$, movable finger length $0.34-0.36$. Pedipalpal trochanter $0.47-0.50 \times 0.28-0.31(1.61-1.68)$, femur $0.89-0.96 \times 0.23(3.87-4.17)$, patella $0.71-0.77 \times 0.27-$ 0.29 (2.63-2.66), chela (with pedicel) $1.53-1.64 \times 0.42-0.46$ (3.57-3.64), chela (without pedicel) $1.42-1.53 \times 0.42-0.46$ (3.33-3.38), hand length (without pedicel) $0.64-0.69$, movable finger length $0.81-0.86(1.25-1.27 \times$ hand $)$. Leg I: trochanter $0.22-0.25 \times 0.17(1.29-1.47)$, femur $0.48-0.54 \times 0.16-0.19(2.84-3.00)$, patella $0.32 \times 0.13(2.46)$, tibia $0.39-0.41 \times 0.11(3.55-3.73)$, basitarsus $0.21 \times 0.08(2.63)$, telotarsus $0.33-0.34 \times 0.07(4.71-4.86)$. Leg IV: trochanter $0.27 \times 0.19$ (1.42), femur + patella $0.90-0.95 \times 0.31-0.32(2.90-2.97)$, tibia $0.72-0.76 \times 0.15-0.16(4.75-4.80)$, basitarsus $0.25-0.28 \times 0.10-0.11(2.50-2.55)$, telotarsus $0.43-0.45 \times 0.10(4.30-4.50)$.

Distribution. China (Guizhou).

Remarks. The other Bisetocreagris species with comparable pedipalpal size (pedipalpal femur $0.89-0.96$, patella $0.71-0.78 \mathrm{~mm}$ in length) are B. tenuis (Redikorzev, 1934), B. annamensis (Beier, 1951), B. kwantungensis (Beier, 1967), B. latona (Ćurčić, 1985) and B. nuratiensis Dashdamirov et Schawaller, 1992. Bisetocreagris gaoi can be distinguished from these species by: carapace with 27 setae (22 in B. latona); pedipalpal femur with granulations on medial face (femur smooth in B. tenuis, B. annamensis and B. kwantungensis); chelal hand smooth (chelal hand with granulations in B. annamensis, B. latona and B. nuratiensis); pedipalpal femur 3.87-4.17 (3.00-3.10 in B. annamensis) times longer than broad; chelal finger longer than hand (chelal finger equal in length to hand in B. tenuis; chelal finger shorter than hand in B. annamensis and B. nuratiensis).

Acknowledgements - We are grateful to Dr. Luyu Wang (Southwest University, Chongqing, China) and Dr. Zhizhong Gao (Hebei University, Baoding, China) for collecting the specimens. We thank the reviewers for suggestions that greatly improved this paper. This work was supported by the National Natural Science Foundation of China (No. 31372154, 31672261) and a Program of Ministry of Science and Technology of Republic of China (2015FY210300) to Feng Zhang.

\section{REFERENCES}

Balzan, L. (1892): Voyage de M. E. Simon au Venezuela (Décembre 1887 - Avril 1888). Arachnides. Chernetes (Pseudoscorpiones). - Annales de la Société Entomologique de France 60: 497-552.

Chamberlin, J. C. (1931): The arachnid order Chelonethida. - Stanford University Publications. Biological Sciences 7(1): 1-284.

Ćurčıć, B. P. M. (1983): A revision of some Asian species of Microcreagris Balzan, 1892 (Neobisiidae, Pseudoscorpiones). - Bulletin of the British Arachnological Society 6: 23-36.

Ćurčić, B. P. M. (1985): A revision of some species of Microcreagris Balzan, 1892 (Neobisiidae, Pseudoscorpiones) from the USSR and adjacent regions. - Bulletin of the British Arachnological Society 6: 331-352. 
Gao, Z. Z., Chen, H. M. \& Zhang, F. (2017): Description of two new cave-dwelling Bisetocreagris species (Pseudoscorpiones, Neobisiidae) from China. - Turkish Journal of Zoology 41 (4): 615-623. https://doi.org/10.3906/zoo-1602-39

Guo, X. B. \& Zhang, F. (2017): Two new species of Bisetocreagris Ćurčić, 1983 (Pseudoscorpiones: Neobisiidae) from China. - Acta Zoologica Academiae Scientiarum Hungaricae 63 (1): 71-82. https://doi.org/10.17109/azh.63.1.71.2017

Harvey, M. S. (1992): The phylogeny and classification of the Pseudoscorpionida (Chelicerata: Arachnida). - Invertebrate Taxonomy 6: 1373-1435. https://doi.org/10.1071/ it9921373

Harvey, M. S. (1999): The Asian species of Microcreagris Balzan (Pseudoscorpiones: Neobisiidae) described by J. C. Chamberlin. - Acta Arachnologica 48: 93-105 https://doi. org/10.2476/asjaa.48.93

HarveY, M. S. (2013): Pseudoscorpions of the World, version 3.0 - Western Australian Museum, Perth. http://museum.wa.gov.au/catalogues-beta/pseudoscorpions [Accessed 28 March 2018]

Judson, M. L. I. (1993): An abnormal, parasitized pseudoscorpion - holotype of Pedalocreagris tethys Curčić ( = Bisetocreagris ussuriensis (Redikorzev), n. syn.) (Arachnida: Chelonethi: Neobisiidae). - Journal of Natural History 27: 1207-1211. https://doi. org/10.1080/00222939300770701

Judson, M. L. I. (2007): A new and endangered species of the pseudoscorpion genus Lagynochthonius from a cave in Vietnam, with notes on chelal morphology and the composition of the Tyrannochthoniini (Arachnida, Chelonethi, Chthoniidae). - Zootaxa 1627: 53-68. https://doi.org/10.11646/zootaxa.1627.1.4

Li, Y. C., SHI, A. M. \& Liv, H. (2017): A new cave-dwelling species of Bisetocreagris Ćurčić (Arachnida, Pseudoscorpiones, Neobisiidae) from Yunnan Province, China. - Entomologica Fennica 28(4): 212-218.

Mahnert, V. \& Li, Y. C. (2016): Cave-inhabiting Neobisiidae (Arachnida: Pseudoscorpiones) from China, with description of four new species of Bisetocreagris Ćurčić. - Revue Suisse de Zoologie 123(2): 259-268. https://doi.org/10.5281/zenodo.155299

Received December 13, 2017, accepted May 9, 2018, published August 1, 2018 